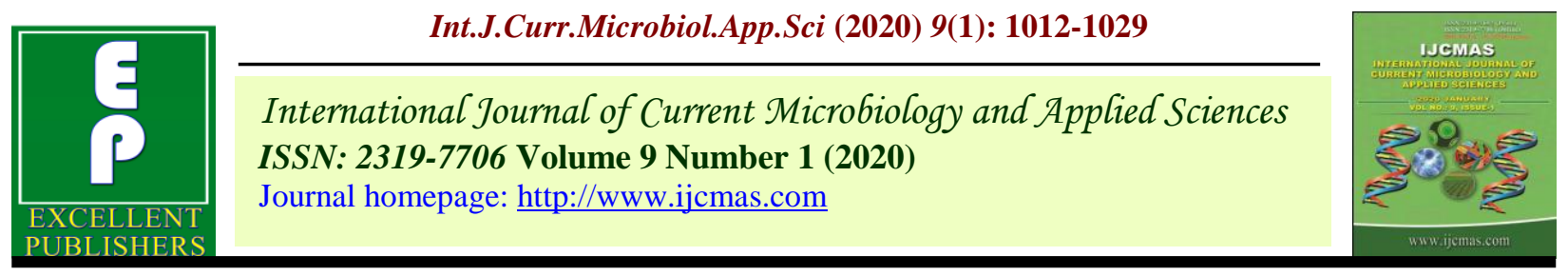

Review Article

https://doi.org/10.20546/ijcmas.2020.901.114

\title{
Double Haploid: An Overview
}

\author{
Omesh Kumar* and Madhu Choudhary
}

Department of Genetics and Plant Breeding, Institute of Agricultural Sciences, Banaras

Hindu University, Varanasi, U.P., 221005

*Corresponding author

\begin{tabular}{|l|}
\hline Ke y w o r d s \\
$\begin{array}{l}\text { Doubled haploid } \\
\text { (DH) Genomics, } \\
\text { Quantitative Trait } \\
\text { Loci (QTL) }\end{array}$ \\
\hline Article Info \\
\hline $\begin{array}{l}\text { Accepted: } \\
\text { 15 December } 2019 \\
\text { Available Online: } \\
\text { 20 January } 2020\end{array}$ \\
\hline
\end{tabular}

Keywords

Doubled haploid (DH) Genomics, Quantitative Trait (QTL)

Accepted:

15 December 2019

20 January 2020

\section{A B S T R A C T}

A doubled haploid (DH) is a genotype developed when haploid cells undergo chromosome doubling. Artificial production of doubled haploids is important in plant breeding. Double haploid (DH) breeding can helps in speedup conventional plant breeding programmes and make early release of cultivars with superior and desirable traits along with greater utility in other research aspects of plant breeding, genetics and genetic engineering. DH's helps in complementing back cross breeding by transferring genes of interest from wild relatives thus breaking genetic barriers. The unique complete homozygous nature of DH's, less time requirement to produce a large number of DH's, absence of heterozygosity, efficiency over conventional systems and absence of gametoclonal variation in DH's make them very valuable material for very important genetic and molecular studies. So, DH's are extensively used for genetic studies like studying inheritance of quantitative traits, Quantitative Trait Loci (QTL) mapping, Genomics, gene identification, whole genome mapping and production of stable transgenic plants.

\section{Introduction}

A plant or line obtained by doubling the chromosome number of a haploid plant is called double haploid. The first report of the haploid plant was published by Blakeslee et al. (1922) in Datura stramonium and Guha and Maheshwari (1964) developed anther culture technique for the production of haploids. Haploid production by wide crossing was reported in barley (Kasha and Kao, 1970) and tobacco (Burk et al., 1979)

Doubled haploid methodologies have now been applied to over 250 species. DHs are very valuable material for very important genetic and molecular studies (Hussain et al., 2012). Haploid line can be developed by the different methods such as distant 
hybridization, Parthenogenesis, anther culture, ovary culture etc. In wheat, distant hybridization methods like Bulbosum technique, wheat $\mathrm{x}$ maize, and wheat $\mathrm{x}$ Imperta cylidrica were used. Out of which wheat $\mathrm{x}$ Imperta cylidrica system is more efficient as compared to other methods. Bulbosum technique in wheat was no longer effective due to the presence of $\mathrm{Kr} 1$ and $\mathrm{Kr} 2$ genes situated on the $5 \mathrm{~A}$ and $5 \mathrm{~B}$ wheat chromosomes which markedly reduce crossability between wheat and bulbosum (Niroula et al., 2009). There are three outstanding double haploids lines of rice were selected from ten doubled haploid lines (DHL's) generated through anther culture from F1506, a cross between C40442B22 and IR1354056321 were had high yield, and uniformity (Lapitan et al., 2004).

Three outstanding DHL's of rice generated from the popular IR64 variety utilizing the anther culture technique had resistance to different soil related stresses such as $\mathrm{P}, \mathrm{K}, \mathrm{Zn}$, $\mathrm{S}$, and $\mathrm{Cu}$ deficiencies. Evaluation of these variants showed improvements on their root system in terms of root length and weight as compared to the seed of IR64 variety (Lapitan et al., 2004).

Using Triticum x Zea crosses for producing $\mathrm{DH}$ lines proved to be efficient in accelerating the release of new cultivars, in the wheat breeding program.

The advantages of the DH system, particularly the advancement of newer, superior crosses, could counterbalance the limitations in the number of crosses and progenies. The utility of DHs in cultivar development, back crossing, genome mapping, hybrid sorting, mutation research, evolutionary studies, gene identification, cytoplasmic research and transgenic plant development make them the best material for genetic improvement and genetic studies.

\section{Approaches for double haploid production}

The importance of haploids in the field of plant breeding and genetics was realised long ago. Their practical application, however, has been restricted due to very a low frequency $(<$ $0.001 \%$ ) of their formation in nature. The process of apomixis or parthenogenesis (development of embryo from an unfertilized egg) is responsible for the spontaneous natural production of haploids. Many attempts were made, both by in vivo and in vitro methods to develop haploids but the success was much higher by in vitro techniques.

\section{In vivo techniques for haploid production}

There are several methods to induce haploid production through in vivo techniques.

Some of them are listed below:

- Distant hybridization crosses followed by chromosome elimination

- Bulbosum Technique

- Parthenogenesis

○ Inducer based approach

\section{Distant hybridization methods}

Hybrids can be produced by elimination of one of the parental genomes as a result of distant (inter-specific or inter-generic crosses) hybridization. There are some methods for producing double haploid in wheat. Cytological analyses performed to reveal the mechanism of chromosome elimination enunciated similar mitotic abnormalities in many hybrids (Laurie and Bennett, 1988, 1989; Mochida et al., 2004). Chromosomes being eliminated tend to be apart from the equatorial plate at metaphase. Sister chromosomes fail to move toward the poles at anaphase and are retained in the cytoplasm to be eliminated from the nuclei. These chromosomes form extra-micronuclei and are finally degraded. In addition to mitosis 
dependent elimination, another pathway of chromosome elimination was proposed in wheat $\times$ pearl millet crosses (Gernand et al., 2005). Micronuclei containing pearl millet chromatin were directly budded and eliminated from interphase nuclei. There are the some distant hybridization methods which are used for the production of haploids in wheat viz., Wheat X Maize Method (Maize Pollen Method), Wheat X Imperta cyllindrica and Wheat X Pearl millet Method. These Inter-generic crosses have been found to be effective for the production of dihaploid plants in wheat. Polyhaploids induction from such crosses is possible because of the preferential chromosomes elimination of the pollen parent during embryo development and haploid plants can be recovered following embryo rescue.

Kasha and Kao for the first time reported haploid barley through barley $\mathrm{x}$ Hordeum bulbosum crosses (H. bulbosum system). Later this system was extended to wheat. This system was also no longer effective due to the presence of $\mathrm{Kr} 1$ and $\mathrm{Kr} 2$ genes situated on the $5 \mathrm{~A}$ and $5 \mathrm{~B}$ wheat chromosomes which markedly reduce the crossability between wheat and bulbosum. Despite the limited success, the efficiency of haploid production in wheat through anther/microspores and wheat $\mathrm{x}$ bulbosum techniques are highly genotype-dependent which limits the use of these techniques in practical wheat breeding.

\section{Wheat X Maize Method (Maize Pollen Method)}

It was 1984 for the first time Zenkteler and Nitzsche reported that embryos are frequently formed when hexaploid wheat pollinated with maize. This raised the considerable interest among wheat breeders and Laurie and Bennett at Plant Breeding Institute, Cambridge started systematic study to confirm the previous reports. They were cytologically able to demonstrate that the maize pollen normally germinates and grows into the wheat embryo sac where the wheat egg is fertilized by the maize sperm nuclei. A hybrid zygote with 21 wheat chromosomes and 10 maize chromosomes is produced. The hybrid zygotes are karotypically unstable; therefore, maize chromosomes fail to move to the spindle poles during cell divisions. Possibly, their centromeres fail to attach to the spindle microtubules due to progressive loss of centromere activity, which is seen as reduction in size and finally the loss of, the primary constriction as reported for $H$. vulgare $\mathrm{x} H$. bulbosum hybrid. The maize chromosomes are rapidly eliminated after a few cell divisions and thus forming a haploid embryo with 21 wheat chromosomes. Wheat $\mathrm{x}$ maize system of crosses following chromosome elimination is an effective and handy tool among available methods for haploid induction in wheat. Its superiority over other techniques includes higher efficacy (2-3 times more efficient for green plant production than the anther culture), simple, less genotype dependent response, less gametoclonal variation and less time consuming

\section{Wheat X Imperta cyllindrica}

This novel haploid induction method has two great advantages in practical application, (1) high frequency of haploid induction irrespective of wheat genotypes, and (2) natural coincidence of flowering period of wheat and I. cylindrica under subtemperate condition. Wheat genotypes affect the crossability with alien species (Inagaki and Mujeeb-Kazi, 1995; Pratap et al., 2005). For example, wheat varieties with dominant $\mathrm{Kr}$ genes, which inhibit alien pollen tube growth, show greatly reduced crossability with many alien species (Riley and Chapman, 1967; Snape et al., 1979; Falk and Kasha, 1981, 1983; Sitch et al., 1985). This restricts the application of haploid induction method by 
crossing with $H$. bulbosum or rye to only some wheat varieties. Although maize pollen is relatively insensitive to wheat genotypes, and therefore maize system has been a practical haploid induction method by chromosome elimination, it is necessary to adjust the flowering period using greenhouse to obtain fresh maize pollen for crossing in subtemperate condition, which increases the costs of this method. I. cylindrica also shows genotype nonspecific crossability with wheat, and the efficiency of haploid induction is comparable to that in using maize. In addition, the coincidence of flowering period between wheat and I. cylindrica enables us to obtain fresh pollen of I. Cylindrical freely. From these points, I. cylindrica is expected to be employed in wheat haploid production alternative to maize (Chaudhary et al., 2005; Pratap et al., 2005).

\section{Procedure}

Hexaploid wheat, Triticum aestivum L. cv. 'Chinese Spring' $(2 n=6 \mathrm{x}=42)$ and Imperata cylindrica $(2 n=2 \mathrm{x}=20)$ were used as female and pollen parents, respectively. The wheat spikes were emasculated before anthesis. The upper small spikelets of the wheat spikes and the central florets of each spikelet were removed, and then anthers were detached from remaining florets. A few days after emasculation, the top of the florets was cut off to expose stigmas. Fresh pollen of $I$. cylindrica was collected from wildly growing plants around the field and applied on the stigmas with a soft brush. The uppermost internodes of wheat stems were injected with $100 \mathrm{mg} / \mathrm{l}$ 2,4-D solution, and $20 \mathrm{mg} / \mathrm{l}$ 2,4-D solution was dropped onto the ovaries $24 \mathrm{~h}$ after pollination. The 2,4-D treatments were repeated for two more consecutive days. Embryos were excised from immature seeds 13 to 16 days after pollination and grown at $20^{\circ} \mathrm{C}$ for several weeks on the MS medium supplemented with $30 \mathrm{~g} / \mathrm{l}$ sucrose, $100 \mathrm{mg} / \mathrm{l}$ myo-inositol, $1 \mathrm{mg} / \mathrm{l}$ thiamine $\mathrm{HCl}, 0.5 \mathrm{mg} / \mathrm{l}$ pyridoxine $\mathrm{HCl}, 0.5 \mathrm{mg} / \mathrm{l}$ nicotinic acid, 2 $\mathrm{mg} / \mathrm{l}$ glycine and $8 \mathrm{~g} / \mathrm{l}$ agar, and adjusted to $\mathrm{pH}$ 5.8 with $\mathrm{NaOH}$. When the regenerated plants grew enough to transplant, they were transferred to soil in a field.

\section{Bulbosum method of double haploid production}

The first to be reported in the early 1970's was the interspecific hybridization of cultivated barley (Hordeum vulgare L.) with $H$. bulbosum L. (Kasha and Kao, 1970). Haploid plantlets of $H$. vulgare are generated as a result of gradual elimination of $H$. bulbosum chromosomes from hybrid embryos between the two species. H. bulbosum is a perennial outcrossing species found in the Mediterranean region. Although there are two cytotypes, diploid $(2 n=2 x=14)$ and tetraploid $(2 n=4 x=28)$, only the diploid form has been used to generate haploid plants of barley. In the procedure the donor plant should be grown in favoulable condition. Emasculation of barley florets is carried out by forming a slit with a forceps in the lemma, through which the three anthers are removed. A freshly collected $H$. bulbosum pollen mixture from four genotypes is applied to receptive stigmas with a paint brush 2-3 days later. Longevity of developing seeds in intergeneric and interspecific hybrids in the Poaceae has been improved by the application of gibberellic acid e.g. GA3 and other plant growth regulators to florets after fertilization. Without GA3 the developing seed degenerate before embryo rescue. GA3 (Sigma G-7645) at $75 \mathrm{mg} / \mathrm{L}+$ $0.05 \%$ Tween 20 applied as a spray to florets 1-2 days after pollination to enhance seed development and embryo size. Early in spring and in the fall, the same treatment is usually repeated one day after the first one. GA3 + 2,4-D + Dicamba at $75 \mathrm{mg} / \mathrm{L} ; 2 \mathrm{mg} / \mathrm{L}$ and 1 $\mathrm{mg} / \mathrm{L}$, respectively, has been used on the day after pollination to promote effectively seed 
longevity. Eleven (summer) to 20 (early spring and late autumn) days after pollination, spikes covered by their labelled brown paper bags are cut off from the plants, immersed to a depth of 5-6 cm in a beaker containing tap water. If seeds are not dissected on the same day, the spikes can be stored up to 15 days in a fridge at $4^{\circ} \mathrm{C}$ in the dark. Seeds are removed from spikes and by the tissue culture technique haploid plant can be develop. The haploid plant can be convert into double haploid by colchicines treatment.

\section{Inducer based approach}

There are at least two important examples of specific genes that can induce haploidy in plants : (i) the indeterminate gametophyte (ig) gene in Zea mays, which induces haploids of both male (androgenetic) and female (gynogenetic) origin; and (ii) the haploid initiator (hap) gene in barley (Hordeum vulgare), which induces haploids of female origin. The plants homozygous for $i g$ when used as female parent, produced 3\% haploids in the progeny and these haploids are found in 2 : 1 ratio with respect to maternal and paternal origin. It has been shown that homozygosity for ig gene induces multiple egg cells (five egg cells) and polar nuclei (seven). Marker genes, $\mathrm{r}^{*}$ (colourless seed, green plants) and $R^{n J}$ (purple pigmented kernel and seedlings) have been combined with ig to allow identification of maternal or paternal haploids in different crosses. In paternal haploids, the genome of male parent is transferred to the cytoplasm of the female parent so that cytoplasmic male steriles with desired nucleus can be easily obtained.In barley, plants homozygous for hap gene produce $1 \%-40 \%$ haploid progeny obtained either on selfing or in crosses as female parent. The plants heterozygous for hap gene (obtained from a cross using hap homozygous plant as female) produce $0.1 \%$ to $10 \%$ haploids, of which half will carry hap gene and the other half the hap gene. Only the latter will be useful since they will not produce haploids (sterile) again in their progeny.

\section{In vitro techniques for haploid production}

In the plant biotechnology programmes, haploid production is achieved by two methods.

\section{Androgenesis}

Haploid production occurs through anther or pollen culture, and they are referred to as androgenic haploids.

\section{Anther culture}

The selected flower buds of young plants are surface-sterilized and anthers removed along with their filaments. The anthers are excised under aseptic conditions, and crushed in $1 \%$ acetocarmine to test the stage of pollen development. If they are at the correct stage, each anther is gently separated (from the filament) and the intact anthers are inoculated on a nutrient medium. Injured anthers should not be used in cultures as they result in callusing of anther wall tissue.The anther cultures are maintained in alternating periods of light (12-18 hr.) and darkness (6-12 hrs.) at $28^{\circ} \mathrm{C}$. As the anthers proliferate, they produce callus which later forms an embryo and then a haploid plant. After this haploid plant are subjected to the colchicine treatment for the production of double haploid plants.

\section{Pollen (microspore) culture}

Haploid plants can be produced from immature pollen or microspores (male gametophytic cells). The pollen can be extracted by pressing and squeezing the anthers with a glass rod against the sides of a beaker. The pollen suspension is filtered to remove anther tissue debris. Viable and large 
pollen (smaller pollen do not regenerate) are concentrated by filtration, washed and collected. These pollens are cultured on a solid or liquid medium. The callus/embryo formed is transferred to a suitable medium to finally produce a haploid plant, and then a diploid plant (on colchicine treatment).

\section{Comparison between anther and pollen cultures}

Anther culture is easy, quick and practicable. Anther walls act as conditioning factors and promote culture growth. Thus, anther cultures are reasonably efficient for haploid production. The major limitation is that the plants not only originate from pollen but also from other parts of anther. This results in the population of plants at different ploidy levels (diploids, aneuploids). The disadvantages associated with anther culture can be overcome by pollen culture.

\section{Gynogenesis}

Haploid plants can be developed from ovary or ovule cultures. It is possible to trigger female gametophytes (megaspores) of angiosperms to develop into a sporophyte. The plants so produced are referred to as gynogenic haploids. Gynogenic haploids were first developed by San Noem (1976) from the ovary cultures of Hordeum vulgare. This technique was later applied for raising haploid plants of rice, wheat, maize, sunflower, sugar beet and tobacco. In vitro culture of unpollinated ovaries (or ovules) is usually employed when the anther cultures give unsatisfactory results for the production of haploid plants. The procedure for gynogenic haploid production is briefly described. The flower buds are excised 24-48 hr. prior to anthesis from un-pollinated ovaries. After removal of calyx, corolla and stamens, the ovaries are subjected to surface sterilization. The ovary, with a cut end at the distal part of pedicel, is inserted in the solid culture medium. Whenever a liquid medium is used, the ovaries are placed on a filter paper or allowed to float over the medium with pedicel inserted through filter paper. The commonly used media are MS, White's, N6 and Nitsch, supplemented growth factors. Production of gynogenic haploids is particularly useful in plants with male sterile genotype. For such plant species, this technique is superior to another culture technique.

\section{Limitations of Gynogenesis}

In practice, production of haploid plants by ovary/ ovule cultures is not used as frequently as anther/ pollen cultures in crop improvement programmes.

\section{Delayed pollination}

This has been observed to enhance the frequency of occurrence of spontaneous haploids in a number of crops. Kihara (1940) while working on $T$. monococcum raised the frequency of haploids by delaying the time of pollination and showed that the two phenomena have a definite correlation. No haploids were produced in 41 individuals pollinated 3-5 days after emasculation, whereas there were three haploids amongst 8 individuals pollinated 9 days after emasculation.

\section{Use of abortive pollen}

As would be expected, the abortive pollen of the same species would be capable of providing the hormonal stimulus for the development of the egg and the endosperm though it may not be able to bring about fertilization.

When this results in the successful stimulation of the egg, a haploid would be the natural result. In a number of plants aberrant pollen 
has been successfully used for this purpose as per example in Rice (Nakamura 1933); Nicotiana glutinosa (Webber 1933).

\section{High and low temperatures}

By subjecting plants to higher as well as lower temperatures than the plant usually experiences, the egg may be stimulated to develop parthenogenetically. By higher temperature treatment i.e. 41 o $\mathrm{C}$ for 45 minutes for 21 hours after pollination Nordenskiold (1939) obtained a haploid plant of rye.

Povolochko (1937) obtained haploids of Nicotiana tabacum by subjecting the female parent to high as well as low temperatures and pollinating it with $N$. alata. by low temperature nearly at the time of fertilization Blakeslee et al. (1922) obtained haploids in Datura stramonium.

\section{Radiation treatment}

The first known haploid to be recognized as such in angiosperms i.e. Datura stramoniwm was obtained by Blakeslee et al. (1922) by applying X-rayed pollen to emasculated flowers. Later, Stadler (1931) obtained ha69ploids in Zea mays by a similar method. Randolph (cfr. Smith 1946), working on the same crop, found that the use of X-ray irradiated pollen raised the frequency of haploids from 1:1550 (normal untreated pollen) to $1: 1040$. In wheat, treatment with $\mathrm{X}$ rays has been tried quite extensively and with fair degree of success.

\section{Chemical treatment}

Deanon (1957) tried various concentrations of aqueous maleic hydrazide, a concentration of 50 ppm., being mostly effective when silks of Golden Cross Bantom Sweet Corn were treated, 24 hours before pollination.

\section{Detection of haploids}

The haploids can be detected by the using of following techniques:-

\section{Morphological techniques}

We have learnt that the vegetative and floral parts and the cell size in haploids are reduced relative to diploids in maize. Greenblatt and Bock (1967) selected 45 seedlings out of 10,000 seedlings, on the basis of size (i.e. thin coleoptiles, etc.) and five of them were found to be monoploids showing some success in screening for haploids. Stomata size, pollen size and pollen abortion can be other criteria to help initial screening, although in each case cytological confirmation will' be essential.

\section{Genetically techniques}

Many genetic marker systems are used for recognizing the haploids. The basic principle involved is that the hybrids and non-hybrids should differ, so that any failure of fertilization and parthenogenetic development of embryo can be recognized in the progeny at the seed stage, seedling stage or adult plant stage. For instance, if a female parent in a cross carries recessive markers and is pollinated by dominant stock, then any recessive progeny would be generally a maternal haploid, although possibility also exists of its being a diploid of one of the following types-

(i) diploid hybrids, mutant or deficient for the marker gene in parent

(ii) diploid hybrids with suppression of dominant marker, due to suppressor gene or a disease

(iii) diploids which are maternal due to apomictic development. If the recognition needs to be done at the seed stage, then the marker should be such that it expresses at the late stage of embryo 
development, such as aleurone colour marker. If screening is to be done at seedling stage, then the marker should clearly express in the seedling (e.g. the purple seedling colour).

This technique of genetic markers has been extensively used in developing maize monoploids. Most extensively used markers include ' $a$ ' for brown colour in aleurone, plant and root and ' $l g$ ' for liguleless, their corresponding dominant markers being ' $A$ ' for purple colour and ' $L g$ ' for liguled characters. If the female parent carries $a$ and/or $l g$, then the monoploids will be recognized by lack of purple colour and/or ligule, in crosses with male parent carrying $A$ and/or $L g$. Another critical marker gene is $R$ allele $\left(R^{n}{ }{ }^{\text {cudu }}\right.$ ) which produces deep pigmentation of aleurone, and thus allows screening at the dormant seed stage.

\section{Chromosome counting}

This is one of the direct and precise methods for ploidy level determination. Haploids and DH plants can be identified by chromosome counting during mitotic or meiotic cell division. Chromosome counting during mitotic division is easy and fast, and can be done by using root tips or other meristamatic tissues. Determination of ploidy by counting mitotic chromosomes is, however, time consuming and difficult especially in crops with small chromosomes such as Brassica napus.

\section{Flow cytometry}

Flowcytometry using DNA selective flourochromes has been considered to be the fast and reliable method for the measurement of nuclear DNA content (Dolezel et al., 2007; Ochatt, 2008). Flow cytometry enables the measurement of ploidy level in an early developmental stage of plantlets emerging from microspore culture. Hence it provides a rapid and simple option for large-scale ploidy determination in early phases.

Flow cytometry also allows the detection of mixoploid (plants with unequal number of chromosome sets in adjacent cells or tissues) regenerants. Although flow cytometry is an efficient technique with high degree of accuracy, the preparation of high quality plant samples for ploidy analysis is the hurdle that accounts for its low utilization in plant breeding.

\section{Mechanism of chromosome doubling (diploidization)}

\section{Endomitosis}

It is described as chromosome multiplication and separation but failure of spindle leads to one restitution nucleus with chromosome number doubled It has also been called 'Nuclear Restitution'.

\section{Endoreduplication}

It is a phenomenon of DNA or Chromosome doubling without Cytokinesis.

\section{C-mitosis}

An artificially induced abortive nuclear division in which the chromosome number is doubled (as that caused by exposure of cells to colchicine)

\section{Nuclear fusion}

It occurs when two or more nuclei divide synchronously and develop a common spindle. Thus, two or more nuclei could result with doubled, polyploid or aneuploid chromosome number. 


\section{Other chromosome doubling agents}

1. Acenanaphthene

2. Chloramphenicol

3. Nitrous oxide

4. Parafluorophenyl alanine

5. Hydroxyquinone

\section{Colchicine}

It is a alkaloid isolated by French chemists P.S. Pelletier and J. Caventon in 1820. It is a toxic natural alkaloid and secondary metabolite, extracted from seed and corn of plants of the genus Colchicum (autumn crocus, Colchicum autumnale, also known as "meadow saffron").

\section{How colchicine work}

When plant parts were treated with appropriate media, the chromosome of treated cells replicated properly, but spindle formation was inhibited and cytolasmic phase of cell division did not take occurs.

\section{Methods of colchicine application}

1. Seed and seedling treatment- 0.1 to 0.4 $\%$ colchicine for 2 to $10 \mathrm{hrs}$. to $24 \mathrm{hrs}$. in vegetables

2. Meristematic cell- 0.05 to $0.1 \%$ for 2 to $10 \mathrm{hrs}$.

3. Presoaked seed with $-0.2 \%$ colchicine solution for 2 to $8 \mathrm{hrs}$.

4. Among all methods of colchicine application, shoot apex treatment at the seedling stage is most effective.

\section{Genetics of double haploid population}

In DH method only two types of genotypes occur for a pair of alleles, A and a, with the frequency of $1 / 2$ AA and $1 / 2$ aa, while in diploid method three genotypes occur with the frequency of $1 / 4$ AA, $1 / 2 \mathrm{Aa}, 1 / 4$ aa. Thus, if AA is desirable genotype, the probability of obtaining this genotype is higher in haploid method than in diploid method. If $\mathrm{n}$ loci are segregating, the probability of getting the desirable genotype is $(1 / 2)^{\mathrm{n}}$ by the haploid method and $(1 / 4)^{\mathrm{n}}$ by the diploid method. Hence the efficiency of the haploid method is high when the number of genes concerned is large.

Studies were conducted comparing DH method and other conventional breeding methods and it was concluded that adoption of doubled haploidy does not lead to any bias of genotypes in populations, and random DH's were even found to be compatible to selected line produced by conventional pedigree method.

\section{Application of double haploids}

In plant breeding double haploid can be used in many ways as describe below.

\section{Cultivar development}

Uniformity is a general requirement of cultivated line in most species, which can be easily obtained through DH production. There are various ways in which DHs can be used in cultivar production. The DH lines themselves can be released as cultivars, they may be used as parents in hybrid cultivar production or more indirectly in the creation of breeders lines and in germplasm conservation. Barley has over 100 direct DH cultivars. According to published information there are currently around $300 \mathrm{DH}$ derived cultivars in 12 species worldwide.

The relevance of DH's to plant breeding has increased markedly in recent years owing to the development of protocols for 25 species. Doubled haploidy already plays an important role in hybrid cultivar production of vegetables, and the potential for ornamental 
production is being vigorously examined. DHs are also being developed in the medicinal herb Valeriana officinalis to select lines with high pharmacological activity. Another interesting development is that fertile homozygous $\mathrm{DH}$ lines can be produced in species that have selfincompatibility systems.

Wheat (Triticum aestivum L.). Several cultivars of wheat have been released in China as a direct result of anther culture (Han, 1986). The development of 'Jinghua No. 1' has been most completely described (Daofen, 1986). From the F1 of a cross between F1 (Lovrin 18 x 5238-036) x Hongliang No. 4, 400 anthers were cultured. Fortysix anther-derived green plants were obtained, from which 28 selffertile plants were produced after chromosome doubling by colchicine. Seed was increased for these 28 lines, and one line was selected for good performance in field evaluations.

After 3 years of regional testing, just 6 years after the initial cross had been made to generate the anther donor, the selected line was released as 'Jinghua No. 1'. More recently, 'Anther Culture 28' has been released in China following a similar protocol, except by selection among the anther-derived plants in the greenhouse for resistance to Erysiphe graminis DC. ex Mérat ; 'Anther Culture 28' demonstrated immunity in the field to the same pathogen (Zhao et al., 1990)

\section{Mapping quantitative trait loci}

Most of the economic traits are controlled by genes with small but cumulative effects. Although the potential of $\mathrm{DH}$ populations in quantitative genetics has been understood for some time, it was the advent of molecular marker maps that provided the impetus for their use in identifying loci controlling quantitative traits. As the quantitative trait loci (QTL) effects are small and highly influenced by environmental factors, accurate phenotyping with replicated trials is needed. This is possible with doubled haploidy organisms because of their true breeding nature and because they can conveniently be produced in large numbers. Using $\mathrm{DH}$ populations, 130 quantitative traits have been mapped in nine crop species. In total, $56 \mathrm{DH}$ populations were used for QTL detection.

\section{Backcross breeding}

In backcross conversion, genes are introgressed from a donor cultivar or related species into a recipient elite line through repeated backcrossing. A problem in this procedure is being able to identify the lines carrying the trait of interest at each generation. The problem is particularly acute if the trait of interest is recessive, as it will be present only in a heterozygous condition after each backcross. The development of molecular markers provides an easier method of selection based on the genotype (marker) rather than the phenotype.

Combined with doubled haploidy it becomes more effective. In marker assisted backcross conversion, a recipient parent is crossed with a donor line and the hybrid (F1) backcrossed to the recipient. The resulting generation $(\mathrm{BC} 1)$ is backcrossed and the process repeated until the desired genotypes are produced. The combination of doubled haploidy and molecular marker provides the short cut. In the back cross generation one itself a genotype with the character of interest can be selected and converted into homozygous doubled haploid genotype. Chen et al. (1994) used marker assisted backcross conversion with doubled haploidy of $\mathrm{BC} 1$ individuals to select stripe rust resistant lines in barley.

\section{Hybrid sorting}

One of the essential steps in haploid breeding involves selection of superior plants among 
haploids derived from F1 hybrids through anther culture. It is popularly described as hybrid sorting and virtually means election of recombinant superior gametes. The haploid method of breeding involving hybrid sorting is considered superior over pedigree and bulk methods, firstly because the frequency of superior gametes is higher than the frequency of corresponding superior plants in F2 generation, and secondly because haploid breeding reduces significantly the time required for development of a new variety. For instance, if we assume that the frequency of superior F, gametes is one in one hundred, then the frequency of homozygous $F_{2}$ plants derived from the fusion of two such superior similar gametes would be one in ten thousand. Therefore, smaller populations of doubled haploids derived from haploids will need to be handled.

The above technique of hybrid sorting has been successfully utilized, particularly in China and Japan, for development of new varieties in several crops. In Japan, an excellent tobacco cultivar, ' $F-21 \mathrm{~V}$ bred through anther Culture, is resistant to bacterial wilt and has a mild smoking quality. In China, more than 100 rice varieties developed using the same technique, gave an increased yield and, therefore, occupy significant areas of rice cultivation

\section{Haploids in other fields}

\section{Haploids in mutation research}

Haploids are also of great interest in basic and applied research on induced mutations, because due to the presence of only one set of chromosomes, even a recessive mutation is immediately expressed. Further, the isolated pollen and single cells can be plated in small Petri plates and screened in large numbers. Mutant cell lines in some crops using haploids have actually been isolated, which showed resistance to various drugs, amino acid analogues, pathotoxins, salts, herbicides, chilling, viruses and nematodes. In tobacco a cell line resistant to methionine-sulphoximine and wild fire disease (caused by Pseudomonas tabaci) has been developed. After differentiation and diploidization, such useful mutations can be incorporated in the regenerated plants in homozygous condition. Varieties may thus be produced whi $\mathrm{k}_{\mathrm{k}}$ show resistance to diseases, salinity and environmental stresses along with better nutritional qualities.

\section{Haploids in evolutionary studies}

A comparison of dihaploids in potato with diploid wild species proved useful in deriving conclusions about the origin of cultivated potato. Since, production of $2 \mathrm{n}$ gametes is common both in dihaploids as well as in diploid species, it is suggested that Andigena, the progenitor of Tuberosum must have originated many times from different but related $2 x$ populations in different locations through sexual polyploidization. Haploids in potato have also been used for crosses with diploid species to conduct genome analysis. The meiosis in hybrids and further generations suggested that wild species differ from cultivated potato in a small number of genes. A study of pachytene chromosomes in potato dihaploids and tomato (diploids, $2 \mathrm{n}=24$ ) suggested closer evolutionary relationship between potato and tomato.

\section{Haploids in genetics}

Disomic inheritance and reduced chromosome number in polyhaploids (e.g. dihaploids in potato) offer special advantage for their use in a variety of genetic studies. Using potato as an example, following uses of haploids in genetic studies in higher plant illustrated: (i) Using electrophoresis, number of genes for several isozymes determined for potato (Simon and 
Peloquin, 1980; Quiros and McHale, 1985). progress has also been made in determining the number of genes for other traits like disease resistance and other agronomic traits, (ii) Using haploids in potato, heritability was also determined for several traits like specific gravity, vine maturity, glucose concentration, tuber dormancy, total yield and tuber weight, (iii) The genotype of a tetraploid can also be determined by extracting and analysing the possible haploids, as has been done for acid gel proteins, several isozymes and self incompatibility in potato,

The recessive alleles are also un-masked in these haploids. Intralocus interactions could be studied using haploids in potato, because at a tetraallelic locus $(A 1 A 2 A 3 A 4)$ in potato, one expects six first order interactions (A1A2, $\mathrm{A} 1 \mathrm{~A} 3, \mathrm{~A} 1 \mathrm{~A} 4, \mathrm{~A} 2 \mathrm{~A} 3, \mathrm{~A} 2 \mathrm{~A} 4$, and $\mathrm{A} 3 \mathrm{~A} 4)$, three second order intractions (A1A2A3, A1A3A4, $\mathrm{A} 2 \mathrm{~A} 3 \mathrm{~A} 4)$ and one third order intraction (A1A2A3A4). As opposed to this, dihaploid will have only one intraction, which partly explains loss of vigour. And recently dihaploid $\mathrm{X}$ wild species crosses were also used for the prepration of RFLP Linkage maps. Doubled haploids derived from F1 hybrids are also being out to increasing use for prepration RFLP maps and are considered to be superior over $\mathrm{F} 2$ progenies.

\section{Haploids in cytogenetic research}

Haploids have also been found to be useful in various areas of cytogenetic research, including their use in production of aneuploidsand determining the basic chromosome number or the nature of polyploidy. In wheat, initially monosomies were produced by E.R. Sears, when haploids were pollinated by normal wheat pollen. The monosomies, presumably resulted due to functioning of egg with restitution nuclei deficient for any individual chromosome. In potato haploids were used for the' production of trisomics using one of the following two procedures : (i) isolation of parthenogenetic aneuhaploid offspring following $A x$ x $2 x$ crosses; (ii) isolation of aneuploids from $3 x \mathrm{x}$ $2 x$ crosses, where $2 x$ is a haploid. In both the schemes, a numbeti of trisomics with $2 \mathbf{n}=25$ were obtained. In tobacco several nullisomics were derived from haploids obtained from sterile monosomies. Haploids have also been' used for the production of alien addition and alien substitution lines in a crop like wheat.

A study of meiosis in haploids also gives evidence for the original base number; in a species or a genus. For instance in bajra (Pennisetum typhoides), occurrence oil some pairing ( 2 bivalents in some cells) suggested that the original base number may be $x=5$. Similar evidence is also available in maize, which is sometimes considered to be an archaic tetraploid. In potato also, chromosome behaviour of dihaploids $(2 n=2 x=24)$ suggested that the base number is $x=12$ and that potato is an autotetraploid. Chromosome behaviour of monoploids in potato $(2 n=x=$ 12) formed only univalents confirming this conclusion.

\section{Advantages of DH's}

The ability to produce homozygous lines after a single round recombination saves a lot of time for the plant breeders. Studies conclude that random DH's are comparable to the selected lines in pedigree inbreeding. The other advantages include development of large number of homozygous lines, efficient genetic analysis and development of markers for useful traits in much less time. More specific benefits include the possibility of seed propagation as an alternative to vegetative multiplication in ornamentals, and in species such as trees in which long life cycles and inbreeding depression preclude traditional breeding methods, doubled haploidy provides new alternatives. 


\section{Disadvantages of DHs}

The main disadvantage with the $\mathrm{DH}$ population is that selection cannot be imposed on the population. But in conventional breeding selection can be practised for several generations: thereby desirable characters can be improved in the population. In haploids produced from anther culture, it is observed that some plants are aneuploids and some are mixed haploid-diploid types. Another disadvantage associated with the double haploidy is the cost involved in establishing tissue culture and growth facilities. The overusage of doubled haploidy may reduce genetic variation in breeding germplasm. Hence one has to take several factors into consideration before deploying doubled haploidy in breeding programmes

Table.1 Varieties developed through double haploid technology

\begin{tabular}{|l|l|l|l|}
\hline Crop & Method followed & Varieties & Country \\
\hline Rice & Anther culture & $\begin{array}{l}\text { Tanfeng 1, Tan Fong 1, Hua Yu 1, Hua } \\
\text { 03, Xin Xiu, Xhongua 8, Ta Be 78, Guan } \\
18\end{array}$ & \\
\hline & Anther culture & Dama & Hungry \\
\hline & Anther culture & Parag 401(ACR 401) & MH, India \\
\hline & Anther culture & CR Dhan 801 & CRRI, India \\
\hline & Anther culture & Patei and Moccoi & Argentina \\
\hline \multirow{2}{*}{ Wheat } & Anther culture & $\begin{array}{l}\text { Hua Pei 1, Lung Hua 1, Jinghua 1, } \\
\text { Yunhua 1, Yunhua 2 }\end{array}$ & China \\
\hline & Anther culture & Kharoba & Morocco \\
\hline & Anther culture & Florin & France \\
\hline & Wheat $x$ Maize & Glosa, Faur F, Liter, Miranda & Romania \\
\hline Tobacco & Anther culture & Tan Yu 1, Tan Yu 2, Tan Yu 3, & China \\
\hline & Anther culture & F211(wilt resistant \& mild smoking) & Japan \\
\hline Barley & H. bulbosum & Mingo, Gwylan & Canada \\
\hline
\end{tabular}


Table.2 Pest and disease resistance lines developed using double haploid technique

\begin{tabular}{|c|c|c|}
\hline Crop \& line & Resistence to & Reference \\
\hline $\begin{array}{l}\text { Barley- Mingo } \\
\text { Q-21681 }\end{array}$ & $\begin{array}{l}\text { Barley yellow mosaic virus } \\
\text { Stem rust, leaf rust and PM }\end{array}$ & $\begin{array}{c}\text { Foroughiwer \& Friedt,1984 } \\
\text { Stoffenson et al.,1995 }\end{array}$ \\
\hline $\begin{array}{l}\text { Rice- Zhonghua no-8 \& } 9 \\
\text { Hwasambye } \\
\text { Hwachengbyeo } \\
\text { Shirayukhine }\end{array}$ & \begin{tabular}{|} 
Blast , high yielding and good quality \\
Leaf blast, BLB, \& rice stripe tenui virus. \\
BPH \& cold tolerance \\
Bacterial blight, rice tenui virus. \\
High yielder, tolerant to major pest and Disease
\end{tabular} & $\begin{array}{c}\text { DDBeeong-geun et al., } 1997 \\
\text { Lee et al., } 1989 \\
\text { Kazahiro \&Terahiro., } 2002 \\
\text { (Japan ) }\end{array}$ \\
\hline Tobacco- Tan yu 3 & Necrotic strain of potato virus & Witherspoon et al., 1991 \\
\hline
\end{tabular}

\section{References}

Barclay, I.R. 1975. High frequencies of haploid production in wheat (Triticum aestivum) by chromosome elimination. Nature 256: 410-411.

Bhojwani, S.S., Razdan, M.K., 1996. Plant Tissue Culture: Theory and Practice, a revised edition. Elsevier, Amsterdam, 467

Bitsch, C., Groger, S., Lelley, T., 1998. Effect of parental genotypes on haploid embryo and plantlet formation in wheat $\mathrm{x}$ maize crosses. Euphytica 103, 319-323.

Blakeslee, A.F., Belling, J., Farnham, M.E., Bergner, A.D., 1922. A haploid mutant in the Jimson weed, Datura stramonium. Science 55, 646-647.

Burk, L.G., Gerstel, D.U.,Wernsman, E.A., 1979. Maternal haploids of Nicotiana tabacum L. from seed. Science 206, 585.

Celiktas, N., Tirykioglu, M., Can, E., Kutlay,D., Hatipoglu, R.,2015. Production of dihaploids in durum wheat using Imperata cylindrica L. mediated chromosome elimination.

Chaudhary, H. K., Singh, S. and Sethi, G.S. 2002. Interactive influence of wheat and maize genotypes on haploid induction in winter x spring wheat hybrids. Journal of Genetics \& Breeding 56: 259- 266.

Chaudhary, H.K., Sethi, G.S., Singh, S., Pratap, A., Sharma, S., 2005. Efficient haploid induction in wheat by using pollen of Imperata cylindrica. Plant Breed. 124, 96-98.

Chen, J.F., Cui, L., Malik, A.A., Mbira, K.G., 2011. In vitro haploid and dihaploid production via unfertilized ovule culture. Plant Cell Tissue Organ Cult. 104, 311319.

Chen, K., Gao, C., 2013. TALENs: customizable molecular DNA scissors for genome engineering of plants. J. Genet. Genomics 40, 271-279.

Chen, X.-W., Cistué, L., Muñoz-Amatriaín, M., Romagosa, S.M., Castillo, A.M., Vallés, M.P., 2007. Genetic markers for doubled haploid response in barley. Euphytica 158, 287-294.

Chen, Y., 1986. The inheritance of rice pollen plant and its application in crop improvement. In: Hu, H., Yang, H. (Eds.), Haploids of Higher Plants In Vitro. Springer-Verlag, Berlin, 118-136.

Daofen, H., 1986. Jinghua No. 1, a winter wheat variety derived from pollen sporophyte. 
In: Hu, H., Yang, H. (Eds.), Haploids of Higher Plants In Vitro. Springer-Verlag, Berlin, pp. 137-148.

Dolezel, J., Greilhuber, J., Suda, J., 2007. Flow cytometry with plants: an overview. In: Doležel, J., Greilhuber, J., Suda, J. (Eds.), Flow Cytometry with Plant Cells. Analysis of Genes, Chromosomes and Genomes. Wiley, Weinheim., pp. 41-65.

Dunwell, J.M., 1985. Embryogenesis from pollen in vitro. In: Zaitlin, M., Day, P., Hollaender, A. (Eds.), Biotechnology in Plant Science: Relevance to Agriculture in the Eighties. Academic Press, Orlando., 49-76.

Dunwell, J.M., 2010. Haploids in flowering plants: origins and exploitation. Plant Biotechnol. J. 8, 377-424.

Elhaddoury, J., Lhaloui, S., Udupa, S.M., Moatassim, B., Taiq, R., Rabeh, M., et al., 2012. Registration of Kharoba: a bread wheat cultivar developed through doubled haploid breeding. J. Plant Regist. 6, 169-173.

El-Hennawy, M.A., Abdalla, A.F., Shafey, S.A., Al-Ashkar, I.M., 2011. Production of doubled haploid wheat lines (Triticum aestivum L.) using anther culture technique. Ann. Agric. Sci. 56, 63-72.

Garcia-Llamas, C., Ramirez, M.C., Ballesteros, J., 2004. Effect of pollinator on haploid production in durum wheat crossed with maize and pearl millet. Plant Breed. 123, 201-203.

Geiger, H.H. and Gordillo, G.A., 2009. Doubled haploids in hybrid maize breeding. Maydica, 54: 485-499.

Grauda, D., Lepse, N., Strazdina, V., Kokina, I., Lapina, L., Miķelsone, A., 2010. Obtaining of doubled haploid lines by anther culture method for the Latvian wheat breeding. Agron. Res. 8, 545-552.

Greenblatt, I.M., Bock, M., 1967. A commercially desirable procedure for detection of monoploids in maize. J. Hered. 58, 9-13.

Grewal, R.K., Lulsdorf, M., Croser, J., Ochatt, S., Vandenberg, A., Warkentin, T.D., 2009. Doubled-haploid production in chickpea (Cicer arietinum L.): role of stress treatments. Plant Cell Rep. 28, 1289-1299.

Griffing, B., 1975. Efficiency changes due to use of doubled-haploids in recurrent selection methods. Theor. Appl. Genet. 46, 367-386.

Grosse, B.A., Deimling, S., Geiger, H.H., 1996. Mapping of genes for anther culture ability in rye by molecular markers. Vortr. Pflanzenzeuchtg. 35, 282-283.

Guha, S., Maheshwari, S.C., 1964. In vitro production of embryos from anthers of Datura. Nature 204, 497.

Guha, S., Maheshwari, S.C., 1966. Cell division and differentiation of embryos in the pollen grains of Datura in vitro. Nature 212, 97-98.

Hofinger, B.J., Huynh, O.A., JankowiczCieslak, J., Müller, A., Otto, I., Kumlehn, J., 2013. Validation of doubled haploid plants by enzymatic mismatch cleavage. Plant Methods 9, 43.

Houben, A., Sanei, M., Pickering, R., 2011. Barley doubled-haploid production by uniparental chromosome elimination. Plant Cell Tissue Organ Cult. 104, 321327.

Hu, H., Zeng, J.Z., 1984. Development of new varieties via anther culture. In: Ammirato, P.V., Evans, D.A., Sharp, W.R., Yamada, Y. (Eds.), Hand Book of Plant Cell CultureCrop Species vol. 3. Macmillan, New York, 65-90.

Hussain, B., Khan, M. A., Ali, Q. and Shaukat, S., 2012, Double haploid production is the best method for genetic improvement and genetic studies of wheat. IJAVMS., 6 (4): 216-228.

Inagaki, M.N., Bohorova, N., 1995. Factors affecting the frequencies of embryo formation and haploid plant regeneration in crosses of hexaploid wheat with pearl millet.Breed. Sci. 45, 21-24.

Inoue, E., Sakuma, F., Kasumi, M., Hara, H., Tsukihashi, T., 2004. Maternal haploidization of Japanese pear through intergeneric hybridization with apple. Acta Horticult. 663, 815-818. 
Iyamabo, O.E., Hayes, P.M., 1995. Effect of selection and opportunities for recombination in double-haploid populations of barley (Hordeum vulgare L.). Plant Breed. 114,131-136.

Jauhar, P.P., Xu, S.S., Baenziger, P.S., 2009. Haploidy in cultivated wheat's: induction and utility in basic and applied research. Crop Sci. 49, 737-755.

Kasha, K.J., Kao, K.N., 1970. High frequency haploid production in barley (Hordeumvulgare L.). Nature 225, 874876.

Kasha, K.J., Song, L.S.P., Park, S.J., Reinbergs, E., 1977. 1977. Fixation of heterosis: comparison of F1 hybrids with their respective homozygous lines developed using doubled haploid procedures. Cereal Res. Commun. 5, 205-214.

Kato, A., 2002. Chromosome doubling of haploid maize seedlings using nitrous oxide gas at the flower primordial stage. Plant Breed. 121, 370-377.

Kaur, P., Bhalla, J.K., 1998. Regeneration of haploid plants from microspore culture of pigeonpea (Cajanus cajan L.). Indian J. Exp. Biol. 36, 736-738.

Kebede, A.Z., Dhillon, B.S., Schipprack,W., Araus, J.L., Bänziger, M., Semagn, K., et al., 2011. Effect of source germplasm and season on the in vivo haploid induction rate in tropical maize. Euphytica 180, 219-226.

Khatun, R., Shahinul Islam,S.M.,Ara, I.,Tuteja,N.,Bari,M.A.,2012. Effect of cold pretreatment and different media in improving anther culture response in rice (Oryza sativa L.) in Bangladesh. Indian J. Biotechnol. 11, 458-463.

Komeda,N., Chaudhary, H.K.,Suzuki, G.,and Mukai, Y., 2007. Cytological evidence for chromosome elimination in wheat $x$ Imperata cylindrica hybrids. Genes Genet. Syst., 241-248.

Kucera, V., Vyvadilova, M. and Klima. M., 2002, Utilisation of doubled haploids in winter oilseed rape (Brassica napus L.) breeding. Czech J. Genet. Plant Breed., 38 (1): 50-54.
Labbani, Z., De Buyser, J., Picard, E., 2007. Effect of mannitol pretreatment to improve green plant regeneration on isolated microspore culture in Triticum turgidum ssp. durum cv. Plant Breed. 126, 565-568.

Lapitan, V. C., Cayaban, E. B., Roferos, L. T., San Valentin, G. O. and Sebastian, L. S., 2004, Utilization of anther culture technique for rice improvement in the Philippines. Crop Science ICSC.

Lashermes, P., Beckert, M., 1988. Genetic control of maternal haploidy in maize (Zea mays L.) and selection of haploid inducing lines. Theor. Appl. Genet. 76, 404-410.

Laurie, D. A. and Bennett, M. D. 1988. Cytological evidence for fertilization in hexaploid wheat $\mathrm{x}$ sorghum crosses. Plant Breeding 100: 73-82.

Laurie, D.A., 1989. The frequency of fertilization in wheat $\times$ pearl millet crosses. Genome 32, 1063-1067.

Laurie, D.A., 1989. The frequency of fertilization in wheat $\times$ pearl millet crosses. Genome 32, 1063-1067.

Laurie, D.A., Bennett, M.D., 1988. The production of haploid wheat plants from wheat $\times$ maize crosses. Theor. Appl. Genet. 76, 393-397.

Lee, C.H., Power, J.B., 1988a. Intraspecific gametosomatic hybridization in Petunia hybrida. Plant Cell Rep. 7, 17-18.

Lee, C.H., Power, J.B., 1988b. Intra- and interspecific gametosomatic hybridization within the genus Petunia. Plant Cell Tissue Organ Cult. 12, 197-200.

Li, A.M., Wei, C.X., Jiang, J.J., Zhang, Y.T., Snowdon, R.J., Wang, Y.P., 2009. Phenotypic variation in the progenies of somatic hybrids between Brassica napus and Sinapis alba. Euphytica 170, 289296.

Li, H., Singh, R.P., Braun, H.J., Pfeiffer, W.H., Wang, J., 2013. Doubled haploids versus conventional breeding in CIMMYT wheat breeding programs. Crop Sci. 53, 74-83.

Liu, D., Zhang, H., Zhang, L., Yuan, Z., Hao, M., Zheng, Y., 2014. Distant 
hybridization: a tool for interspecific manipulation of chromosomes. In: Pratap, A., Kumar, J. (Eds.), Alien Gene Transfer in Crop Plants, Volume 1 Innovations, Methods and Risk Assessment. Springer, 25-42.

Liu, W.,Ming, Y.Z., Polle, A.E., Konzak, C.F., 2002. Highly efficient doubled-haploid production in wheat (Triticum aestivum L.) via induced microspore embryogenesis. Crop Sci. 42, 686-692.

Loo, S.-W., Xu, Z.H., 1986. Rice: anther culture for rice improvement in China. In: Bajaj, Y.P.S. (Ed.), Biotechnology in Agriculture and Forestry 2: Crops I. Springer-Verlag, Berlin, 139-156.

Mago, R., Lawrence, G.J., Ellis, J.G., 2011. The application of DNA marker and doubled haploid technology for stacking multiple stem rust resistance genes in wheat. Mol. Breed. 27, 329-335.

Maheshwari, S., Tyagi, A.K.,Malhotra, K., 1980. Induction of haploidy frompollen grains in angiosperms - the current status. Theor. Appl. Genet. 58, 193-206.

Maluszynski, M., Szarejko, I., Sigurbjörnsson, B., 1996. Haploid and mutation techniques. In: Jain, S.M., Sopory, S.K., Veilleux, R.E. (Eds.), In Vitro Haploid production in Higher Plants, Vol 1: Fundamental Aspects and Methods. Kluwer Academic Publishers, Dordrecht, the Netherlands, 67-93.

Ming-hui, Yan, H., Bing-yan, Yong-ying, B., Shi-jie, W., Li-juan, M. and Xin-you, Z.,2011. Breeding of newly licensed wheat variety Huapei 8 and improved breeding strategy by anther culture. African Journal of Biotechnology.10(85),19701-19706.

Mukai, Y. and Gill, B. S. 1991. Detection of barley chromatin added to wheat by genomic in situ hybridization. Genome 34: 448-452.

Murovec, J., Bohanec, B., 2012. Haploids and doubled haploids in plant breeding. In: Abdurakhmonov, I. (Ed.), Plant Breeding. InTech Europe, Croatia. ISBN: 978-953307- 932-5, 87-106.
Niroula, R. K., and Bimb, H. P., 2009, Overview of wheat $\mathrm{x}$ maize system of crosses for dihaploid induction in wheat. World Applied Sciences Journal, 7 (8): 1037-1045.

Nitsch, J.P., Nitsch, C., 1969. Haploid plants from pollen grains. Science 163, 85-87.

Ochatt, S.J., 2008. Flow cytometry in plant breeding. Cytometry A 73, 581-598.

Pickering, R.A., 1984. The influence of genotype and environment on chromosome elimination in crosses between Hordeum vulgare $\times$ Hordeum bulbosum. Plant Sci. Lett. 34, 153-164.

Pickering, R.A., Morgan, P.W., 1985. The influence of temperature on chromosome elimination during embryo development in crosses involving Hordeum spp., wheat (Triticum aestivum L.) and rye (Secale cereale L.). Theor. Appl. Genet. 70, 199206.

Pollacsek, N.,1991. Management of the ig gene for haploid induction in maize. Agronomie, 12:247-251.

Prem, D., Gupta, K., Agnihotri, A., 2004. Doubled haploids: a powerful biotechnological tool for genetic enhancement in oilseed Brassicas. In: Srivastava, P.S.,Narula, A., Srivastava, S. (Eds.), Plant Biotechnology and Molecular Markers. Anamaya Publishers, New Delhi, India, 18-30.

Prem, D., Gupta, K., Agnihotri, A., 2005. Effect of various exogenous and endogenous factors on microspore embryogenesis in Indian mustard (Brassica juncea [L.] Czern \& Coss). In Vitro Cell Dev. Biol. Plant 41, 266-273.

Prem, D., Gupta, K., Sarkar, G., Agnihotri, A., 2008. Activated charcoal induced high frequency microspore embryogenesis and efficient doubled haploid production in Brassica juncea. Plant Cell Tissue Organ Cult. 93, 269-282.

Ravi,M.,Marimuthu,M.P.A., Tan, E.H., Maheshwari, S., Henry, I.M.,MarinRodriguez, B., et al., 2014. A haploid genetics toolbox for Arabidopsis thaliana. Nat. Commun. 5, 5334.. 
Sanchez-Díaz, R.A., Castillo, A.M., Vallés, M.P., 2013. Microspore embryogenesis in wheat: new marker genes for early, middle and late stages of embryo development. Sex. Plant Reprod. 26, 287 296.

Sangthong, R., Chin, D.P., Hayashi, M., Supaibulwattana, K., Mii, M., 2009a. Direct isolation of female germ units from ovules of Petunia hybrida by enzymatic treatment without releasing somatic protoplasts. Plant Biotechnol. J. 26, 369375.

Sangthong, R., Chin, D.P., Supaibulwatana, K.,Mii,M., 2009b. Gametosomatic hybridization between egg cell protoplast and mesophyll protoplast of Petunia hybrida. Plant Biotechnol. J. 26, 377-383.

Santra, M., Ankrah, N., Santra, D.K., Kidwell, K.K., 2012. An improved wheat microspore culture technique for the production of doubled haploid plants. Crop Sci. 52, 2314-2320.

Săulescu, N. N., Ittu, G., Giura, A., Mustatea, P., and Ittu, M., 2012. Results of using Zea method for doubled haploid production in wheat breeding at nardi fundulea - Romania. Romanian agricultural research, 29:3-8.

Shen, J.H., Li, M.F., Chen, Y.Q., Zhang, Z.H., 1982. Breeding by anther culture in rice varieties improvement. Sci. Agric. Sin. 2, $15-19$.

Sitch, L.A., Snape, J.W., Firman, S.J., 1985. Intra-chromosomal mapping of crossability genes in wheat Triticum aestivum. Theor. Appl. Genet. 70, 309314.

Snape, J.W., Sitch, L.A., Simpson, E., Parker, B.B., 1988. Tests for the presence of gametoclonal variation in barley and wheat doubled haploids produced using the Hordeum bulbosum system. Theor. Appl. Genet. 75, 509-513.

Weber, S., Wilfried, L., Friedt, W., 2004. Efficient doubled haploid production in Brassica napus via microspore colchicine treatment in vitro and ploidy determination by flow cytometry. WeberLühs-Friedt GCIRC-Bulletin, 1-6.

Xu, L., Najeeb, U., Tang, G.X., Gu, H.H., Zhang, G.Q., 2007. Haploid and doubled haploid technology. Adv. Bot. Res. 45, 181-216.

Xu, Y., Wan, J., Prasanna, B.M., 2014. Breeding informatics of crop improvement: current status and prospects. Plant Animal Genome XXII Conference. January 11-15, 2014, San Diego, California, p. W 379.

Ying, C., Chofu, L., Yunbi, X., Ping, H., Lihuang, Z., 1996. Gametoclonal variation of microspore derived doubled haploids in indica rice agronomic performance isozymes and RFLP analysis. J. Genet. Genomics 23, 196204.

Zhao, Y., He, X., Wang, J., Liu, W., 1990. Anther culture-28 a new disease resistant and high-yielding variety of winter wheat. In: Bajaj, Y.P.S. (Ed.), Biotechnology in Agriculture and Forestry 13: Wheat. Springer-Verlag, Berlin, 353-362.

\section{How to cite this article:}

Omesh Kumar and Madhu Choudhary. 2020. Double Haploid: An Overview. Int.J.Curr.Microbiol.App.Sci. 9(01): 1012-1029. doi: https://doi.org/10.20546/ijcmas.2020.901.114 